\title{
GAMIFICAÇÃO DE TESTES PSICOLÓGICOS PARA ALFABETIZAÇÃO E COMPETÊNCIAS ESPACIAIS DE CRIANÇAS PORTADORAS DE AUTISMO E SÍNDROME DE DOWN
}

\section{GAMIFICATION OF PSYCHOLOGICAL TESTS FOR LITERACY AND SPECIAL SKILLS OF CHILDREN WITH AUTISM AND DOWN SYNDROME}

\author{
Julia Costa Oliva ${ }^{1}$, Grad. \\ Maria Clara Rollemberg Lima de Oliveira ${ }^{2}$, Grad. \\ Isabella Geovanini Otto da Silva ${ }^{3}$, Grad. \\ Helena Patrício de Oliveira Gomes ${ }^{4}$, Grad. \\ João Marcos Bittencourt ${ }^{5}$, DSc. \\ Giuseppe Amado de Oliveira ${ }^{6}$, DSc. \\ (1) Universidade Federal Fluminense - UFF \\ juliaoliva@id.uff.br \\ (2) Universidade Federal Fluminense - UFF \\ rollemberg_maria@id.uff.br \\ (3) Universidade Federal Fluminense - UFF \\ igeovanini@id.uff.br \\ (4) Universidade Federal Fluminense - UFF \\ helenagomes@id.uff.br \\ (5) Universidade Federal Fluminense - UFF \\ joaombittencourt@gmail.com \\ (6) Universidade Federal Fluminense - UFF \\ gamado@id.uff.br
}

\begin{abstract}
Psicologia, Design, Ergonomia, Aprendizagem, Produto
As tecnologias assistivas auxiliam em diversos casos. Considerando as síndromes cognitivas, ainda há uma carência de produtos voltados para estas deficiências que ajudem os profissionais da área de neuropsicopedagogia. Será apresentado neste trabalho um produto voltado para auxílio educacional que utiliza ferramentas psicológicas, a fim de recolher novas informações do paciente, promover o aumento das capacidades de leitura, escrita e autoconhecimento das crianças e estimular o melhor rendimento do tempo de consulta. O método de desenvolvimento utilizado consistiu na Intervenção Ergonomizadora a partir do acompanhamento do tratamento de cinco crianças com síndromes distintas: Transtorno do Espectro Autista (TEA) e Síndrome de Down. Espera-se com este trabalho estimular o uso do design colaborativo e incentivar a busca e elaboração de novas formas de tratamento.
\end{abstract}

\section{Psychology, Design, Ergonomics, Learning, Product}

Assistive technology aids in many different situations. Concerning cognitive disorders, the area of neuropsychopedagogy lacks of products focused on helping professionals with the treatment. A product that focuses on educational aid is being presented in this article, using psychological tools in order to assist collecting new pieces of information concerning the patient, increasing reading, writing skills as well as self knowledge and promote a better use of the session's time. The method used was Ergonomizer Intervention with observations of five children's behavior, which were encompassed in distinctive disorders: Autism Spectrum and Down Syndrome. With this article, it's expected to promote the use of collaborative design and encourage the search for new treatment solutions.

\section{Introdução}

A deficiência cognitiva por muitas vezes dificulta as relações e as interações interpessoais de uma criança, por conta de preconceito e do atraso no aprendizado. É preciso desenvolver maneiras de facilitar a reintegração dessas pessoas na sociedade como um todo, principalmente na fase infantil, onde está se construindo laços e adquirindo mais conhecimentos. Para isso, profissionais da saúde de diferentes especialidades atuam em conjunto na tentativa de criar estímulos para esse 
desenvolvimento. Esse trabalho pode ser apoiado por produtos de tecnologia assistiva, desenvolvidos objetivando dar suporte para esses tratamentos.

Um estudo divulgado em 2018 pelo CDC (Center of Diseases Control and Prevention), órgão ligado ao governo dos Estados Unidos, revela que a cada cinquenta e nove crianças nascidas uma será portadora do Transtorno de Espectro Autista (TEA). Estima-se, portanto, que o Brasil possui mais de 3 milhões de pessoas com Autismo. Observando o caso da Síndrome de Down, estatísticas sugerem que, em escala mundial, um em cada mil nascidos vivos possui a Trissomia 21. Em escala nacional um em cada setecentos nasce com Síndrome de Down, totalizando cerca de 270 mil brasileiros no ano de 2016. Com esse número elevado, é possível ter noção da importância de um tratamento adequado visando a participação plena da sociedade como um todo.

A legislação brasileira garante direitos à pessoas com deficiência. A lei $\mathrm{n}^{\circ} 7.853$, de 24 de outubro de 1989, visa garantir os direitos básicos dos deficientes, dentre eles a educação. A lei $\mathrm{n}^{\circ}$ 10.845, de 5 de março de 2004 institui o programa de complementação ao atendimento educacional especializado às pessoas portadoras de deficiência, assegurando o direito à educação especializada de pessoas portadoras de deficiência. Enquanto a lei ${ }^{\circ}$ 13.146 de 6 de julho de 2015 institui a Lei Brasileira de Inclusão da Pessoa com Deficiência (Estatuto da Pessoa com Deficiência), destinada a assegurar e a promover, em condições de igualdade, o exercício dos direitos e das liberdades fundamentais por pessoa com deficiência, visando à sua inclusão social e cidadania..

A necessidade da inclusão de crianças e a preparação das mesmas para a sociedade, bem como a maior divulgação das síndromes cognitivas nas camadas populares, fez crescer a busca por tratamento. Dados do Censo Escolar na Educação Básica dos anos de 2007 a 2012, juntamente com microdados do Censo Escolar MEC/INEP, foram utilizados para fazer uma análise de matrículas em Escolas Especializadas e de Ensino Comum referentes ao âmbito nacional, com dados mais atualizados, entre 2007 a 2014. Considerando os alunos entre sete e dezessete anos da educação especial, nota-se que o percentual de matrículas de alunos incluídos em classe comum também vem subindo gradativamente, passando de $87,1 \% \mathrm{em}$ 2014 para $92,1 \%$ em 2018. Esses dados revelaram que a matrícula de crianças em ensino comum aumentaram em relação às escolas especializadas, porém as escolas comuns nem sempre possuem a infraestrutura adequada para recebê-las e atender suas necessidades.

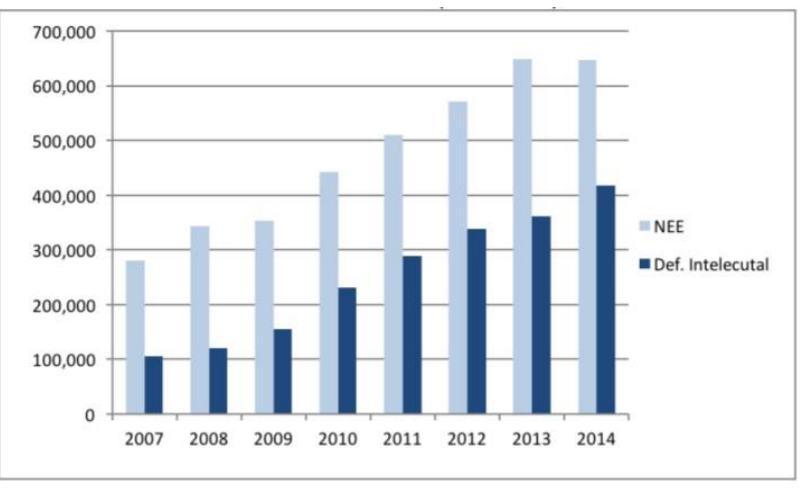

Imagem 1: Matrículas nacionais de alunos com necessidades educativas especiais e de alunos com deficiência intelectual (2007-2014), no ensino comum.

O sistema educacional também não demonstra estar preparado para receber essas crianças. Estima-se que apenas 30\% das escolas brasileiras que, registram matrículas de alunos com deficiência, possuem atendimento educacional especializado. Entretanto, somente $26 \%$ possuem salas multifuncionais e apenas $4 \%$ dos professores que atuam nessas escolas têm formação específica em educação especial.

\section{O objetivo deste trabalho é apresentar o} desenvolvimento de um jogo que estimule crianças com deficiências cognitivas a realizar atividades ligadas à educação, englobando a leitura, escrita e reconhecimento motor e social. Sendo estas responsáveis pelo conhecimento do próprio corpo e sua extensão e pela associação de conhecimento prévio, como cores, o mundo ao seu redor, utilizando como base capacidades como observar e relacionar objetos a uma cor já conhecida. O jogo deve servir como uma ferramenta capaz de recolher novas informações sobre a criança e sua realidade, desta forma a terapeuta poderá adequar melhor o tratamento às suas necessidades, fazer recomendações e encaminhamentos.

\subsection{Gamificação}

Jogos e brincadeiras sempre foram atrativos para a sociedade, especialmente jovens. É através destas atividades que conceitos podem ser aprendidos ou estimulados, pois estão na estrutura essencial do jogo. A possibilidade de completar o objetivo 
apresentado, sem aplicar os conceitos previamente implementados, se torna baixa. A partir disso, é possível pensar em aplicar esses conteúdos a serem aprendidos em um jogo, permitindo uma nova maneira de absorção e implementação de acordo com as necessidades apresentadas.

Existem diversas atividades que, muitas vezes, tem sua execução comprometida por ser dada como chata ou repetitiva, já que falta dinamicidade nas suas tarefas. A gamificação vem como uma solução para o problema do tédio, ao passo que traz o preceito que uma atividade do cotidiano pode virar um jogo.

Diferentes empresas empregam esse estilo de atividade atualmente, já que ao fazer algo divertido os funcionários apresentam uma melhora no seu rendimento. Geralmente, jogos dentro dessa categoria vem acompanhados de metas a serem atingidas, aumentando assim o engajamento por parte dos jogadores. Em conjunto com as metas, sistemas de recompensa e a participação voluntária também tem um grande papel no melhor desempenho no jogo. A vontade de ganhar na atividade e a recompensa que receberiam ao conquistar vitórias mantém os participantes interessados, levando ao sucesso da atividade proposta.

Ao ser empregado em ambiente escolar e de aprendizado, o processo de gamificação mostrou bons resultados, crianças se mostraram inclinadas a se interessarem mais por atividades quando chamadas de jogos ou brincadeiras. Ao transformar atividades destinadas à aprendizagem em jogos, educadores conseguiam melhor colaboração da parte dos alunos, que prestavam mais atenção e se empenhavam mais em realizá-las, consequentemente aprendendo mais facilmente sobre o tema abordado no jogo.

Um dos pontos importantes quanto à gamificação é a necessidade de transformar o tema abordado em algo jogável, especialmente em escolas, já que o termo "brincar" ou "jogar", muitas vezes, é mais interessante para crianças do que atividades educativas que remetem à estudar. A necessidade maior é transformar o jogo em algo divertido, pois a partir da diversão, as crianças não rejeitam o jogo.

Com isso em mente, o grupo decidiu trazer a gamificação para o projeto, dada a área em que seria realizado. $\mathrm{O}$ suporte que era necessário para fazer as atividades mais atrativas para os pacientes foi encontrado na decisão de torná-lo um jogo, atendendo assim às necessidades expostas ao grupo de designers.

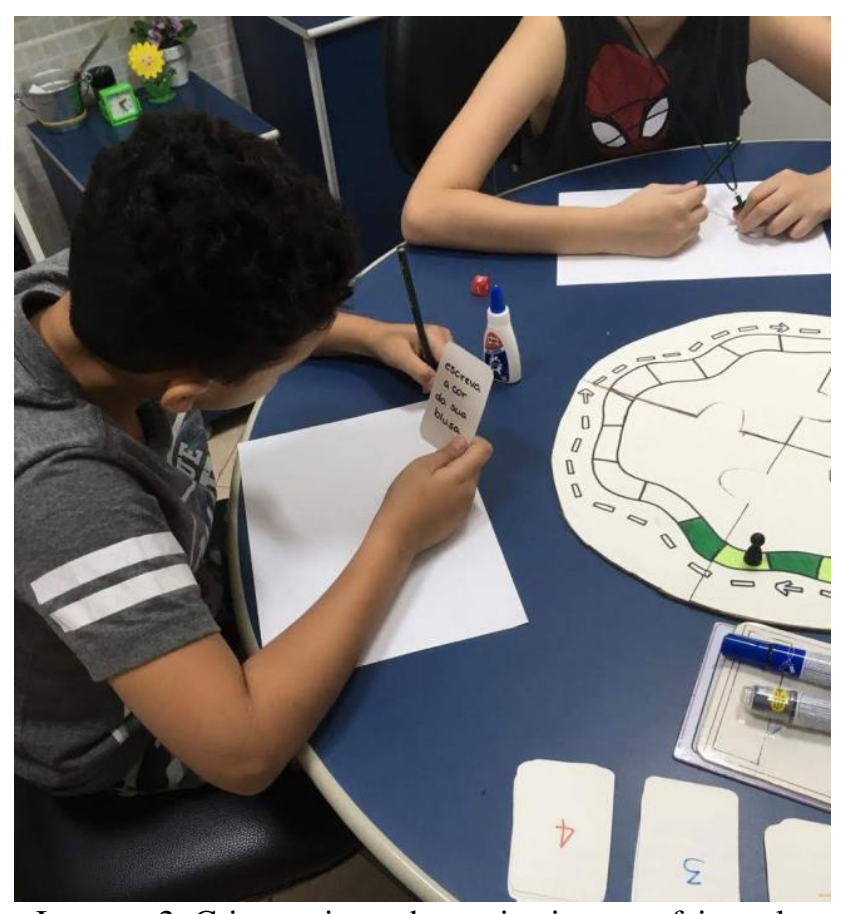

Imagem 2: Crianças jogando o primeiro teste feito pelo

\section{Método} grupo.

Por se tratar de um projeto que envolve apoiar o trabalho de profissionais da área de Neuropsicopedagogia, foi utilizado o método da Intervenção Ergonomizadora (Moraes e Mont'avão, 2010). A metodologia foi selecionada por oferecer subsídios metodológicos para análise da situação de trabalho e, subsequentemente, desenvolvimento projetual de uma solução. Este método se divide em quatro grandes partes fundamentais, sendo elas: parecer ergonômico; diagnose; projetação e validação.

O projeto foi desenvolvido por uma equipe de designers de uma Universidade Federal em parceria com a Associação Fluminense de Reabilitação (AFR), instituição especializada na reabilitação de crianças, jovens e adultos com deficiência. Nessa unidade, foi selecionado conjuntamente com a associação trabalhar com o setor de Neuropsicopedagogia. As análises se concentraram em cinco pacientes, sendo um com Síndrome de Down e quatro com TEA. O projeto teve duração de quatro meses e a análise do trabalho foi focada no acompanhamento do tratamento dessas cinco 
crianças, no qual era realizado duas vezes por semana.

Os dados foram coletados durante as consultas de 30 minutos com os mesmos cinco pacientes, e em alguns casos, com mais de um paciente simultaneamente, para melhor enfoque da análise. Durante as sessões foram realizadas observações diretas, fotografias e medições de tempo para registrar a performance durante a realização do trabalho. Também foram realizadas entrevistas em geral, antes da realização das consultas, para maior aprofundamento e compreensão sobre os problemas observados em sessões anteriores; além de coletar informações mais específicas sobre as atividades que eram passadas para os pacientes, problemas posturais e a relação da criança quanto à atividade, desde a compreensão do que lhe é solicitado até a execução da mesma. Informações da terapeuta sobre a evolução e comportamentos anteriores da criança em relação às atividades já presente no setor foram consideradas e analisadas para a concepção do produto final.

A fim de coletar dados mais pontuais e validações iniciais, foram feitos testes com um mock-up em escala 1:1 com materiais alternativos. O mock-up visava testar se o dimensionamento e controle do tempo através do tabuleiro funcionaria como idealizado, se os níveis de dificuldade propostos adequavam-se às diferentes faixas etárias atendidas pelo setor e se a linguagem estava de acordo com o necessário para a compreensão e execução da atividade pelo paciente.

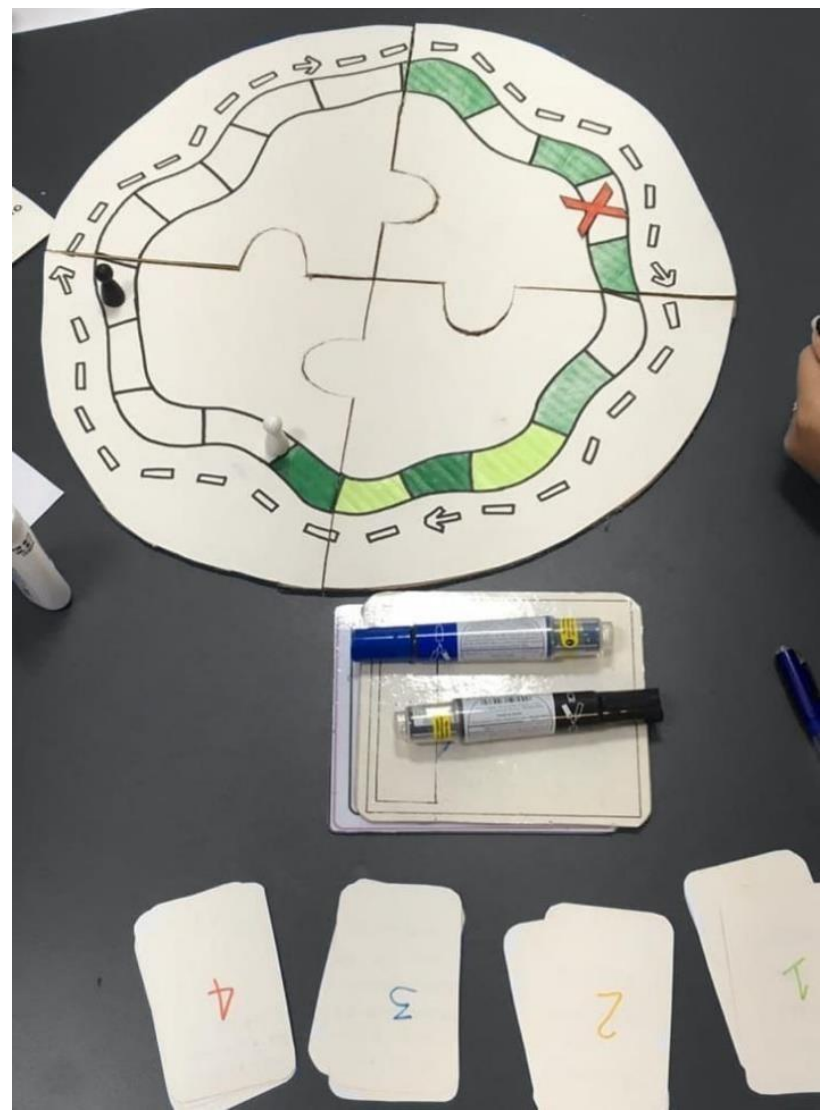

Imagem 3: Mock-up do tabuleiro em seu primeiro teste.

\section{Resultados}

Nesse item serão apresentados os resultados desse trabalho em duas etapas, num primeiro momento resultados na análise da situação de trabalho e identificação dos problemas. Em seguida, a proposta projetual e como foi realizada a validação.

\subsection{Análise do Trabalho}

O trabalho das terapeutas consiste em auxiliar na aprendizagem e desenvolvimento cognitivo dos pacientes, para melhor integrá-los à sociedade. No setor, competências como escrita, leitura e operações matemáticas são estimuladas, bem como a relação do paciente com outras pessoas e a si mesmo. O trabalho envolve o desenvolvimento de atividades pré estabelecidas pela terapeuta junto aos pacientes, como jogos de tabuleiro já existentes ou até mesmo jogos criados pelas próprias profissionais. Por haver um desfalque de produtos focados para os tipos de síndromes que selecionamos aprofundar os estudos, as terapeutas desenvolviam ideias de jogos ou atividades de maneira improvisada, criando tarefas que pudessem ser utilizadas pelos pacientes nas sessões. Essas atividades criadas de forma rústica acabaram por ajudar bastante na confecção do nosso 
produto final, pois pudemos avaliar cada ideia e, de maneira coesa, incluí-las de alguma forma no nosso produto.

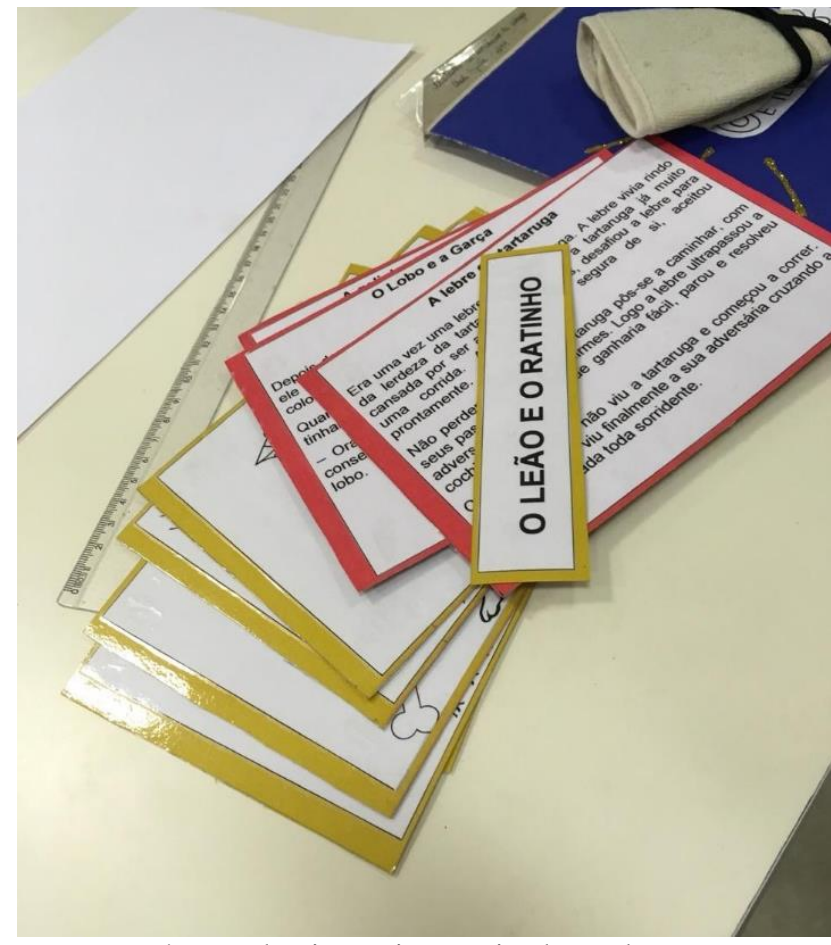

Imagem 4: Um dos jogos improvisados pelas terapeutas do setor.

Entretanto, percebemos que as crianças não conseguiam manter seu foco por muito tempo, pois os produtos e tabuleiros já existentes no local não despertavam seu interesse e/ou eram de difícil compreensão, causando nelas tédio, inquietação e teimosia. Portanto, convencer o paciente de que a atividade deveria ser realizada era algo que ocorria com frequência, o que tem como consequência o não aproveitamento de parte da sessão. Para que seja efetivo, muitas vezes o paciente deve confiar na terapeuta com quem se trabalha, um processo que demanda tempo para se tornar realidade e atrapalha quando relacionado à obtenção de informações sobre os pacientes.

As atividades feitas durante as sessões, de duração média de trinta minutos, mudam a cada visita do paciente, para que diferentes habilidades sejam testadas e estimuladas, além de evitar a repetição excessiva de uma mesma atividade e uma possível rejeição por elas. Se a criança gosta da atividade, maiores as chances de chegar ao fim desta, caso contrário, é preciso mudar a proposta da atividade, para que seja alterada e moldada às suas necessidades. Atividades como jogos para reescrever frases e representar as mesmas por meio de desenhos eram dadas pelas terapeutas; porém, exercícios que envolvessem matemática, reconhecimento espacial, como encontrar cores pela sala e se movimentar pela mesma, estavam em falta de acordo com as profissionais.

A maior parte dos jogos era comprada em lojas convencionais, portanto a maioria não era pensada para este público e tinha seu propósito ou regras modificados para que se encaixassem no que as terapeutas precisavam desenvolver durante a sessão. Muitas vezes, as peças não eram as ideais para o manuseio por parte das crianças portadoras das síndromes mencionadas, sendo frágeis ou pequenas demais. Os tabuleiros e regras também eram confusos em alguns dos jogos, o que dificultava o andamento da sessão, fazendo com que a terapeuta tivesse que explicar diversas vezes a mesma informação que era de difícil compreensão por parte dos pacientes.

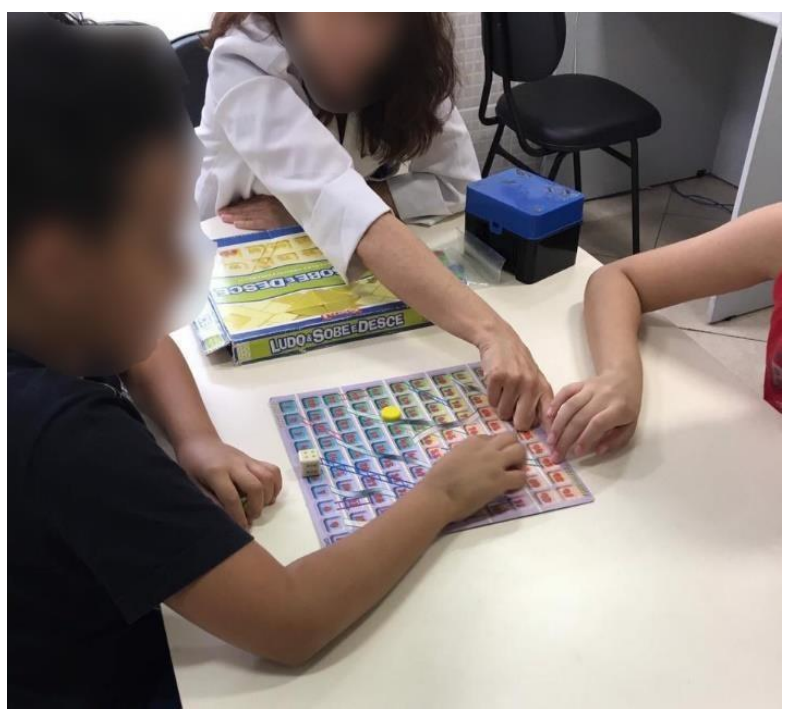

Imagem 5: Pacientes utilizando um dos jogos comprados em lojas convencionais.

Cada sessão começa com a chegada do paciente no setor, sendo recepcionado pela terapeuta designada para trabalhar com ele. A atividade previamente escolhida pelas terapeutas é anunciada, e então o paciente começa a realizá-la. Muitas vezes ocorrem problemas com o início e a continuação da atividade, já que é comum ter a atenção da criança dispersa, levando a falta de cooperação por parte da mesma. Se a atividade proposta é finalizada dentro do tempo determinado pela terapeuta, o paciente tem direito a uma recompensa: alguns minutos brincando com o que deseja ou escolhendo a próxima atividade a ser realizada. Se houver problemas com o desenrolar do exercício, a terapeuta tentará 
convencer a criança a terminar o que foi proposto até o tempo de consulta chegar ao fim. Uma vez que os minutos de sessão acabaram, a criança é entregue aos responsáveis e retornará na semana seguinte.

Em horários em que muitos pacientes estão presentes simultaneamente, mesmo tendo uma terapeuta os atendendo exclusivamente, o nível de distração aumenta no setor, o que pode atrapalhar no andamento da sessão, já que os pacientes, muitas vezes, já são inquietos e o quadro pode vir a piorar com muitos estímulos do ambiente. O setor é disposto de salas pequenas, o que dificulta na realização de atividades em que os pacientes devem se mover pelo espaço para aumentar seu reconhecimento espacial ou até mesmo no isolamento da criança em casos especiais.

A partir da análise de dados e visitas ao setor, aos poucos o quadro de problematizações dentro do ambiente foi desenvolvido. Um problema que pôde ser percebido rapidamente foi a questão da má utilização de tempo útil da consulta pelo fato de muitos pacientes não se interessarem pelas atividades propostas; havia uma grande necessidade de convencê-los, o que ocupava muito tempo dos trinta minutos disponíveis para consulta. E muitas vezes, mesmo com o paciente se interessando pelo exercício, haviam peças ou informações extremamente confusas, o que diminuía a vontade de concluí-lo. O espaço do setor também foi avaliado, já que era um espaço muito pequeno para a quantidade de crianças e terapeutas que ficavam presentes durante todo o dia, levando a problemas envolvendo postura principalmente por parte das terapeutas, muitos ruídos no ambiente que poderiam atrapalhar o desenrolar da sessão, fazendo com que, novamente, as atividades e avaliações acerca dos pacientes fossem prejudicadas. Com base nas informações relacionadas aos problemas no setor coletadas, deu-se início à busca por soluções imediatas e a longo prazo.

\subsection{Produto Proposto}

Todo o jogo foi pensado para passar a ideia de uma grande aventura para o paciente, despertando o seu interesse através das cores chamativas e dos personagens cartunizados, assemelhando-se aos programas televisivos de seu cotidiano. As crianças que apresentam as síndromes observadas neste projeto, muitas vezes, se distraem facilmente e, se não há interesse na atividade, relutam em não terminar o que lhes foi proposto.

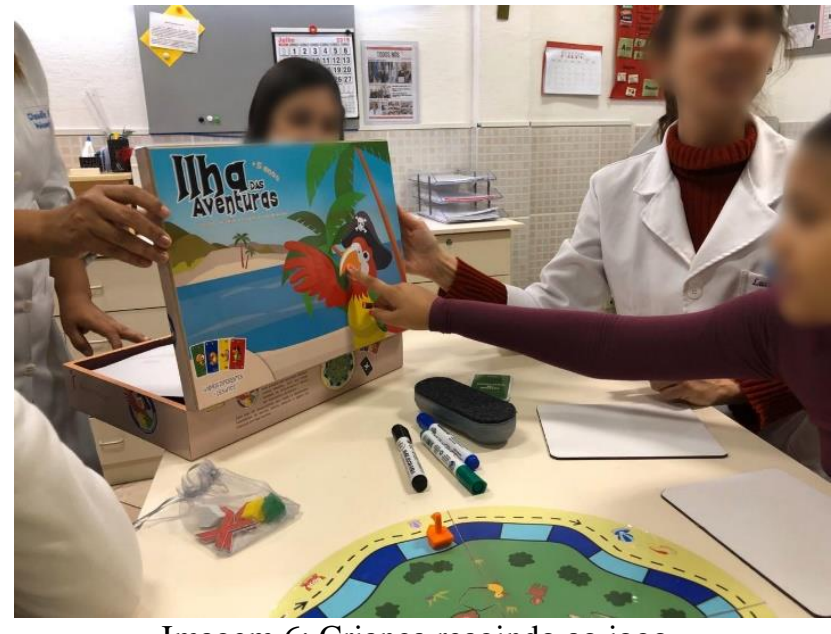

Imagem 6: Criança reagindo ao jogo.

Foi desenvolvido então um tabuleiro dividido em quatro seções, possibilitando haver o controle da duração da partida pelas terapeutas, para que houvesse melhor aproveitamento do tempo de consulta; cada seção corresponde a aproximadamente oito minutos. A divisão do tabuleiro permitiu a autonomia da terapeuta em escolher o tempo de duração ideal da partida, podendo este variar de uma partida de curta duração a uma partida que ocupe o tempo integral da consulta. $\mathrm{O}$ tabuleiro ser desmontável também tem a função de facilitar o armazenamento, diminuindo o espaço necessário para tal. $O$ ponto de chegada, marcado pelo "x" não é fixo, sendo posicionado pela terapeuta, adequando-se ao número de seções do tabuleiro utilizados.

O dado utilizado durante o jogo é personalizado, permitindo novamente uma forma alternativa do controle do tempo. O dado possui quatro faces contando de um (1) a quatro (4) e duas faces de ação: o "desafio" e o "troque de lugar". A face "desafio" pede para a criança escolher uma carta desafio do nível determinado pela terapeuta e realizar a ação proposta. A face "troque de lugar" permite que os jogadores troquem de lugar fisicamente, como uma dança das cadeiras, ou de lugar no tabuleiro, invertendo a posição dos peões entre os participantes. As faces de ação proporcionam uma nova perspectiva do paciente em relação ao jogo, visto que, a qualquer momento ela será desafiada a realizar uma ação imprevista e deverá adaptar-se à nova realidade do jogo.

Para finalizar o jogo é necessário chegar ao " $x$ ", entretanto, a pedido das terapeutas, foi desenvolvido um sistema de recompensa para aqueles que não 
PUC-Rio Pontifícia Universidade Católica do Rio de Janeiro Departamento de Artes \& Design | PPGDesign

LEUI | Laboratório de Ergodesign e Usabilidade de Interfaces

atingiram o objetivo primeiro É comum, para que haja mais interesse nas atividades, usarem o sistema de recompensa para manter os pacientes entretidos, já que facilita a conclusão da sessão.

Com esse ponto levantado, foi decidido utilizar de um recompensa no final da partida, porém, não querendo instigar a competição de forma errônea, então, foi determinado que o prêmio seriam adesivos de estrelas que o vencedor deveria compartilhar com seus adversários, assim, ao final, todos seriam recompensados recebendo algo por trabalharem em conjunto e terminarem a atividade. $\mathrm{O}$ jogador que chega ao destino, abre um baú de madeira posicionado no centro do tabuleiro, e compartilha com os demais jogadores adesivos, desenvolvendo e estimulando a competitividade saudável e o senso de comunidade. Ao permitir que todos sejam recompensados por terminar a atividade, as crianças evitam frustrações e ações agressivas, bem como permite o estímulo a terminar outras atividades, por ser uma recompensa diferente das propostas no setor.

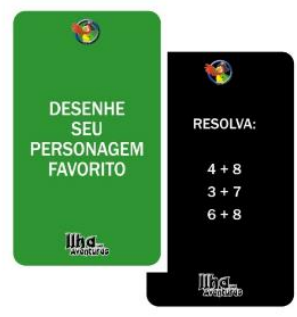

NÍVEL 1

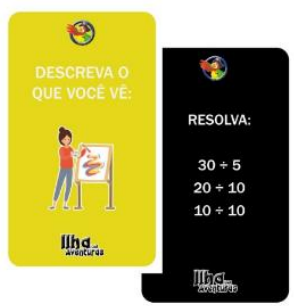

NÍVEL 3

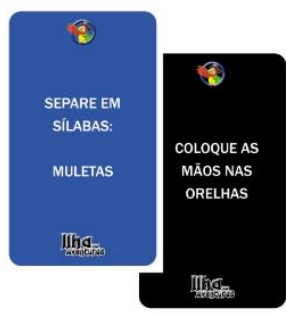

NÍVEL 2

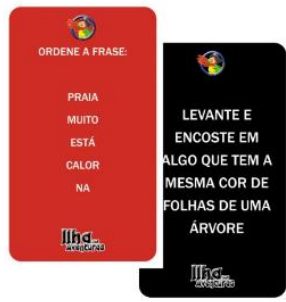

NÍVEL 4
Imagem 7: Exemplos de cartas de cada nível e seus desafios.

Os quatro níveis, compostos de quarenta cartas atividade e dez desafios cada, foram desenvolvidos baseados nos testes psicológicos de Machover, conhecido como teste da figura humana, Teste de Goodenough, que determina a maturidade intelectual e Testes Psicométricos, que medem coeficientes como a atenção, memória e compreensão de leitura. Em todos os níveis citados a seguir o teste de Goodenough foi empregado. As cartas desafio tem como propósito estimular a criança a ir além de suas capacidades conhecidas. As atividades físicas propostas visam retirar a criança do ambiente centralizado na mesa de consulta e que explore seus arredores de forma mais lúdica.

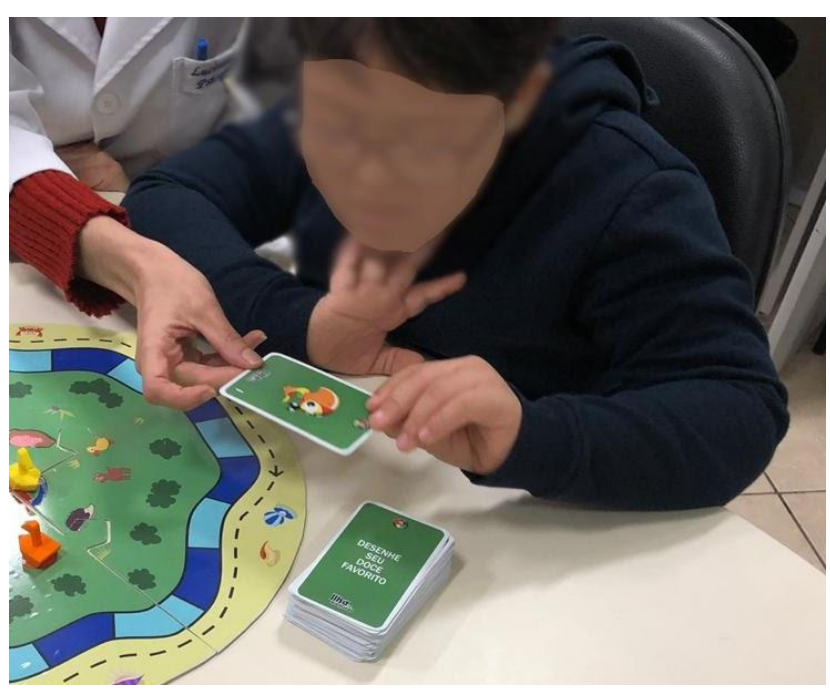

Imagem 8: Criança participando da atividade.

Utilizando o teste de Machover, o nível um foi elaborado pensando nas crianças ainda não alfabetizadas. Trabalhando com o ato de desenhar, dando ênfase a figura humana, e funciona como ferramenta auxiliar para as terapeutas identificarem problemas no ambiente familiar e como a mente da criança funciona em relação a representação do seu cotidiano. Observando o tempo que a criança leva, os comentários feitos por ela durante o ato de desenhar e quais escolhas foram feitas para a representação, como o sexo da figura humana, é possível compreender melhor a realidade do paciente, permitindo, inclusive a detecção de abusos ou situações que comprometam a integridade e segurança da criança. As cartas desafio deste nível apresentam atividades como matemática básica, soma e subtração, e mobilizações físicas, como encostar partes do próprio corpo com as mãos.

O nível dois foi projetado utilizando testes psicométricos focados na atenção e memória a longo prazo de crianças em fase inicial de alfabetização. Trabalhando com divisão silábica, busca auxiliar na descoberta de uma outra possível patologia que acompanha as síndromes focadas: Dislexia. Fazendo uso de palavras presentes no cotidiano, o nível dois serve, também, como uma ferramenta de exercício educacional para a fase de alfabetização, instigando o paciente a associar a escrita com o cenário social em que está inserido. As cartas desafio trabalham 
com as mesmas operações e mobilizações que o nível um.

O nível três foi desenvolvido utilizando o teste psicológico de Machover. Com o intuito de permitir a terapeuta a perceber como a criança vê o mundo a partir de uma imagem apresentada. As cartas estimulam a criança a mostrar sua representação particular através de uma imagem, como um boneco andando de bicicleta, possibilitando que uma mesma carta apresente diferentes interpretações dependendo do paciente. Diferente do nível um, em que o paciente é estimulado a desenhar o que foi requisitado, o nível três pede que a criança se expresse e descreva usando palavras a informação recebida. Este nível serve, também, como ferramenta de estimulação à escrita. As cartas desafio trabalham com operações matemáticas de multiplicação e divisão, enquanto as cartas motoras buscam criar uma relação entre conhecimento e ambiente, como encostar em algum objeto na sala da mesma cor de uma fruta.

Utilizando o teste de Goodenough, o quarto e último nível trabalha com a criação de sentido. Palavras embaralhadas são apresentadas e pede-se que a criança organize e monte uma frase com sentido. Essas atividades possibilitam a terapeuta a perceber a ordem que o cérebro do paciente funciona, sentido direto ou indireto, melhorando a comunicação e adaptação de outras atividades às necessidades da criança. $\mathrm{O}$ último nível permite, também, observar novamente a atenção do paciente, ao observar se alguma palavra foi esquecida ou escrita errada. Ao observar esses esquecimentos e a frequência com que ocorrem, os profissionais podem observar se existe a presença de outra patologia recorrente nos casos estudados: Transtorno de Déficit de Atenção (TDA). As cartas desafio trabalham com simplificação de frações e atividades motoras, que misturam movimentação coordenada de diferentes partes do corpo e relação conhecimento-ambiente.

O manual do jogo foi escrito pensando novamente na participação do paciente. Usando uma linguagem simples o manual pode ser lido tanto pela terapeuta quanto pela criança, tornando-se mais uma ferramenta de incentivo a leitura. Simulando as instruções de um pirata de como encontrar o grande tesouro, o texto vale-se do lúdico para estimular a criança a realizar completamente a atividade. $\mathrm{O}$ manual foi preso à parte interna da tampa da caixa, para evitar a perda e danificação das instruções.

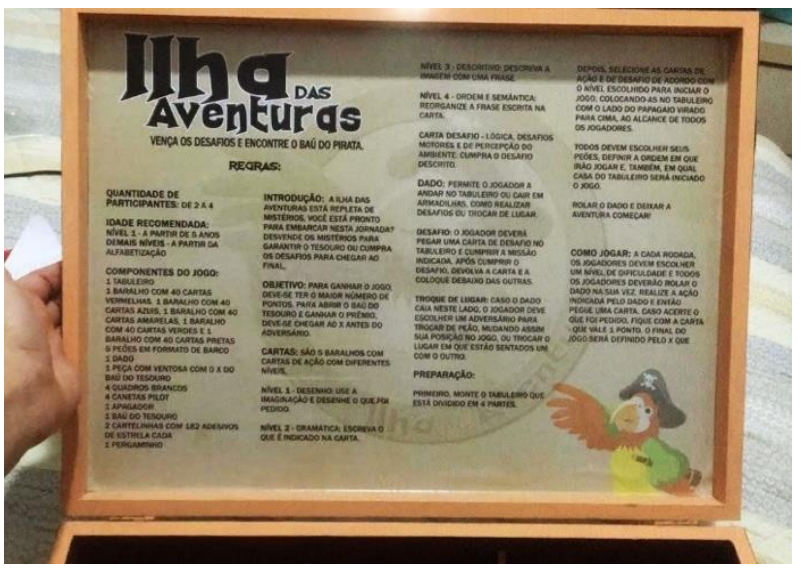

Imagem 9: Manual preso à tampa da caixa.

\section{Validação}

A validação inicial se deu a partir de um mock-up de papelão desenhado à hidrocor, em escala real (1:1). A utilização de materiais alternativos permitiu a confirmação de características, como as proporções do tabuleiro, e a modificação de outras como a necessidade de um dado personalizado e tamanho das cartas. O mock-up foi testado com as cinco crianças, citadas anteriormente, com idades entre sete e onze anos. A dinâmica da validação funcionava da seguinte forma: uma integrante do grupo explicava a atividade e jogava junto com a criança e a terapeuta durante o tempo de consulta. Ao fim de cada partida as opiniões das crianças e da terapeuta eram recolhidas e levadas em consideração, moldando de acordo com as necessidades e as observações.

Objetivando melhorias, foram discutidas e propostas algumas implementações de métodos para a otimização da consulta: adicionar níveis nas cartas do jogo, de acordo com diferentes graus de escolaridade; permitir à terapeuta a personalização do tempo de uma sessão através do jogo, assim como tornar possível a intervenção direta da profissional na escolha do nível de dificuldade; constatou-se indispensável a inclusão de imagens coloridas e animadas, por permitirem maior interesse das crianças, que por consequência diminui consideravelmente a dispersão e a desistência da atividade antes de completá-la. Melhorar as relações interpessoais das crianças também era necessário para o processo da consulta e por esse motivo foi feito um jogo para até quatro participantes que permitisse a troca de informações entre os pacientes e melhorasse seu contato com outras pessoas. 
Os níveis com dificuldades claras e distintas, baseados nos testes psicológicos citados anteriormente, em conjunto com as cartas desafio, atribui a cada conjunto uma boa variedade de atividades e mantém a sensação de novidade por um tempo maior. A curiosidade, já aguçada pelas patologias, é utilizada de maneira positiva, estimulando a continuidade da atividade.

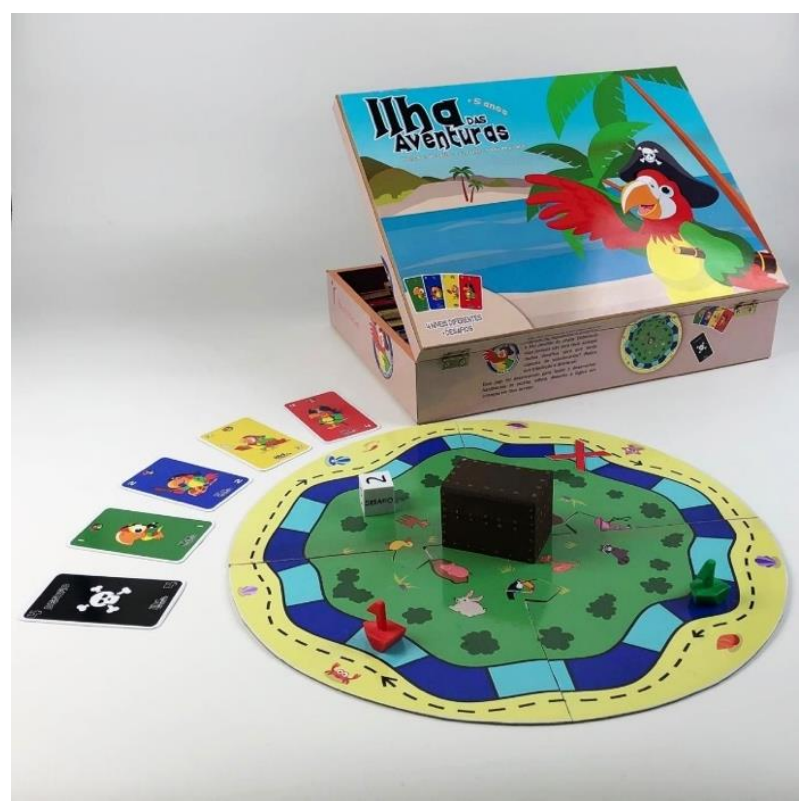

Imagem 10: Jogo aberto e seus componentes principais.

\section{Discussão}

As características do produto final foram definidas ao longo de pesquisas durante o período de estudos e observações. $\mathrm{O}$ grande objetivo era melhorar o uso do tempo durante as sessões, permitindo a realização de mais atividades e estímulos durante o tempo restrito das sessões. Já nos testes feitos com protótipos, houve uma diferença considerável quando se trata da otimização da consulta, pois já não era mais necessário tirar parte do tempo para a explicação da atividade pelo fácil entendimento do jogo e do tabuleiro. Com esse novo tempo ganho, era possível adicionar atividades à sessão ou até trabalhar mais as habilidades da criança como um todo.

Antes da realização do produto, os pacientes eram muito dispersos por conta de características próprias de suas síndromes ou de fatores externos, e após a observação da utilização do produto nas consultas, foi visível o aumento de concentração e pôde-se confirmar também o aumento da produtividade. Durante uma das consultas, a terapeuta fez a observação de que essa teria sido a primeira vez que aquela determinada paciente teria completado uma atividade desde que iniciou seu tratamento.

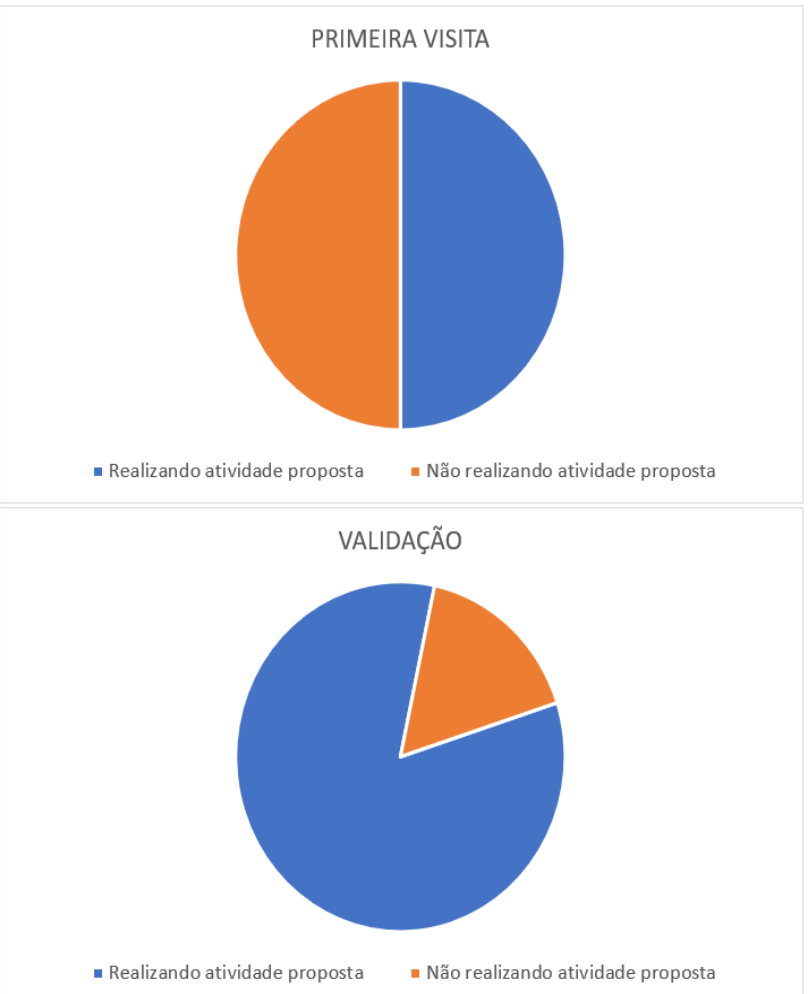

Imagem 11: Gráficos comparativos de rendimento da criança durante a consulta na primeira visita e na validação do produto.

Em diversas ocasiões o grupo juntamente com as profissionais do setor discutiu sobre abranger patologias menos frequentes no setor. A possibilidade de permitir constante desenvolvimento e crescimento do jogo como um todo foi levado em consideração para a execução final. Permitir que peças novas e novas cartas sejam adicionadas à composição do jogo foi um fator crucial para que o produto pudesse moldar-se às necessidades mutáveis do setor.

Entre os limites desse trabalho destaca-se a especificidade do público com o que desenvolveu-se esse projeto. O setor selecionado não abrangia uma grande diversidade de patologias, possuindo majoritariamente pacientes com Transtorno do Espectro Autista e Síndrome de Down, dificultando assim a validação com outros tipos de deficiências e um maior aprofundamento de pesquisas. A idade dos pacientes atendidos na Neuropsicopedagogia também era um fator limitante, pois atendia apenas crianças até doze anos. O contato com pacientes de diferentes idades e síndromes poderá futuramente permitir uma atualização do jogo, com novas 
PUC-Rio Pontifícia Universidade Católica do Rio de Janeiro Departamento de Artes \& Design | PPGDesign

LEUI | Laboratório de Ergodesign e Usabilidade de Interfaces

atividades adequadas para um espectro maior de tratamento. Visando essa e outras melhorias, o grupo de projeto ainda mantém contato com a instituição, planejando novas cartas para enriquecer as atividades, possivelmente abrangendo outras patologias.

\section{Conclusão}

Seguindo os estudos desenvolvidos em torno da concepção do produto final, o jogo como um todo possui bastante relevância no cenário de educação inclusiva. Cada vez mais as pessoas se importam e olham com outros olhos para pessoas com as síndromes citadas anteriormente. $\mathrm{O}$ mercado não possui muita variedade de produtos próprios para a alfabetização de crianças com distúrbios cognitivos, principalmente de jogos educativos, que muitas vezes são de difícil entendimento para elas, com regras complicadas e design confuso, que não estimulam a concentração.

Desse modo, através do acompanhamento dessas crianças em seus respectivos tratamentos, foram feitas observações que auxiliaram a aprofundar os estudos, assim como a importante participação das terapeutas com suas sugestões, completamente relevantes e necessárias para o auxílio do grupo para a preparação de um jogo que atendesse esse nicho negligenciado. Ao fim de cada consulta acompanhada o grupo pedia também a opinião dos pacientes, convidando-os a participar da criação do jogo que viria a ser deles.

O método da Intervenção Ergonomizadora também foi um fator fundamental para a diagnose $\mathrm{e}$ desenvolvimento do projeto, auxiliando o grupo na percepção dos problemas e na identificação das necessidades mais urgentes a serem resolvidas.

O jogo possibilitou que as crianças reconhecessem suas capacidades e elevou sua autoestima, mostrando para as mesmas que elas eram capazes de realizar as atividades e se divertirem ao mesmo tempo. Espera-se, com essa proposta, contribuir para o desenvolvimento cognitivo de crianças com síndromes variadas e estimular outros projetos colaborativos voltados para educação inclusiva que ajude a aumentar a variedade de produtos desse segmento.

\section{Referências Bibliográficas}

BRASIL. Lei $\mathrm{N}^{\mathrm{o}} 7.853$, de 24 de outubro de 1989. Dispõe sobre o apoio às pessoas portadoras de deficiência, sua integração social, sobre a Coordenadoria Nacional para Integração da Pessoa Portadora de Deficiência. Disponível em: <http://www.planalto.gov.br/ccivil_03/Leis/L7853.h tm>. Acesso em: 02 set. 2019.

BRASIL. Lei No 10.845, de 5 de março de 2004. Institui o programa de complementação ao atendimento educacional especializado às pessoas portadoras de deficiência, e dá outras providências. Disponível em:

<http://www.planalto.gov.br/ccivil_03/_Ato2004200 6/2004/Lei/L10.845.htm>. Acesso em: 02 set. 2019.

BRASIL. Lei No 13.146, 6 de julho de 2015. Institui a Lei Brasileira de Inclusão da Pessoa com Deficiência. Disponível em: <http://www.planalto.gov.br/ccivil_03/_ato2015201 8/2015/lei/113146.htm>. Acesso em: 13 set. 2019.

COMAR, Suyane Elias. Teste de Goodenough, teste do desenho da figura humana. Disponível em:

$<$ https://www.infoescola.com/psicologia/testedegoodenough-teste-do-desenho-da-figurahumana/>. Acesso em: 02 set. 2019.

COSTA, Leandro Demenciano. O que jogos de entretenimento têm que os educativos não têm: 7 princípios para projetar jogos educativos eficientes. Rio de Janeiro: Ed. PUC-Rio, 2010.

DA SILVA, Roselaine B. Ferreira; PASA, Aline; CASTOLDI, Dieime Reis; SPESSATTO, Francieli. $O$ desenho da figura humana e seu uso na Avaliação Psicológica. Disponível em: $<$ https://periodicos.pucpr.br/index.php/psicologiaar gumento/article/view/19837>. Acesso em: 02 set. 2019.

DOWN, Federação. Síndrome de Down.

Disponível em:

<http://federacaodown.org.br/index.php/sindromededown/>. Acesso em: 16 mar. 2020.

DOWN, Instituto Mano. O que é a Síndrome de Down. Disponível em :

<http://www.manodown.com.br/instituto/o-que-easindrome-de-down/>. Acesso em: 02 set. 2019. 
FRANCO, Simone. Escolas enfrentam despreparo para incluir alunos com deficiência. Disponível

em:

$<$ https://www12.senado.leg.br/noticias/materias/201 6/02/25/escolas-enfrentam-despreparo-para-

incluiralunos-com-deficiencia>. Acesso em: 13 set. 2019.

INEP. Censo Escolar 2018 revela crescimento de $18 \%$ nas matrículas em tempo integral no ensino médio. Disponível em:

$<$ http://portal.inep.gov.br/artigo/-

/asset_publisher/B4AQV9zFY7Bv/content/censoesc olar-2018-revela-crescimento-de-18-nasmatriculasem-tempo-integral-no-ensinomedio/21206>. Acesso em: 02 set. 2019.

JUNIOR, Francisco Paiva. Quantos autistas há no Brasil? Disponível em:

<https://www.revistaautismo.com.br/naocategorizado/quantos-autistas-ha-no-brasil/> . Acesso em: 20 mar. 2020.

LESSA, Lecyr Miranda de Paiva. Estudo da escala de Goodenough. Disponível em:

<http://bibliotecadigital.fgv.br/ojs/index.php/abpt/ar ticle/viewFile/13411/12315>. Acesso em: 02 set. 2019.

MEC. Prorrogado o prazo de indicação para as salas multifuncionais. Disponível em: <http://portal.mec.gov.br/component/tags/tag/32101 -educacaoespecial>. Acesso em: 13 set. 2019.

MORAES, Anamaria de; MONT'ALVÃO, Claudia. Ergonomia: Conceitos e aplicações. 4. ed. rev. atual. e aum. Teresópolis: 2AB, 2012. 223 p. v. 1. ISBN 978-85-86695-49-0.

OLIVEIRA, Carolina. Um retrato do autismo no Brasil. Disponível em:

<http://www.usp.br/espacoaberto/?materia=umretrat o-do-autismo-no-brasil>. Acesso em: 02 set. 2019.

\section{SCHOOL, Johns Hopkins. Johns Hopkins}

Bloomberg American Health Initiative Releases Special Public Health Reports Supplement.

Disponível em:

<https://www.jhsph.edu/news/newsreleases/2018/jo hns-hopkins-bloomberg-americanhealth-initiativereleases-special-public-healthreportssupplement.html>. Acesso em: 14 set. 2019.
Dedicamos esse projeto a todas as pessoas com algum tipo de deficiência cognitiva. Principalmente aos portadores do Transtorno de Espectro Autista e Síndrome de Down, em especial às crianças que nos acolheram em seu tratamento e ajudaram a elaborar este projeto com suas ideias e comentários únicos. Agradecemos ao professor João Marcos Bittencourt, pelas orientações, esclarecimentos e tempo disposto a ajudar o grupo com suas infinitas dúvidas. Ao professor Giuseppe Amado, pela oportunidade de trabalhar com esse tema e por todas as orientações dadas em aula. À monitora Rafaela Borges, por sempre estar disposta a ajudar. Somos gratas também à associação de reabilitação em que trabalhamos, por nos receber e permitir que fizéssemos este projeto junto a eles e por ceder seu tempo e seus profissionais. À Valéria, que mediou os contatos entre a AFR e o grupo e também pela ajuda prestada em uma situação delicada. À Moara, que ajudou o grupo a se sentir acolhido no setor de Neuropsicopedagogia. À Luciana, por ajudar o grupo a entender melhor os pacientes e por todas as informações valiosas. À Claudia, fundamental em momentos de crise e que nos deixou super confortáveis, possibilitando o melhor cenário para essa pesquisa. E por fim, aos nossos familiares e amigos por todo apoio.

\section{Agradecimentos}

